Jurnal Sistem Informasi (Journal of Information Systems). 2/12 (2016), 63-73

DOI: http://dx.doi.org/10.21609/jsi.v12i2.468

\title{
ANALISIS DAN PERANCANGAN TATA KELOLA TI MENGGUNAKAN COBIT 4.1 DOMAIN PLAN AND ORGANISE (PO) DAN ACQUIRE AND IMPLEMENT (AI): STUDI KASUS PT XYZ
}

\author{
Amanda Yunia Zafarina, Murahartawaty, dan Rahmat Mulyana
}

Sistem Informasi, Fakultas Rekayasa Industri, Universitas Telkom, Jl. Telekomunikasi Terusan Buah Batu, Bandung, 40257, Indonesia

Email: amandayuniaz@gmail.com,murahartawaty@gmail.com,rahmat.moelyana@gmail.com

\section{Abstract}

\begin{abstract}
Companies that implement information technology should have the ability to manage the governance and the implementation of the Information Technology Governance (ITG). Application of IT Governance may support the organization in building a framework to direct and decide the utilization of IT according to the organization needs aligned with its vision, mission, values, strategy, and culture. Keputusan Minister of BUMN is the reference on good IT governance through its implementations in stateowned enterprises. According to the IT governance framework mentioned in PER-02/MBU/ 2013, COBIT 4.1 is a framework that focuses on the relationship between IT and enterprise business. Hence, in this research, COBIT (Control Objective for Information and Related Technology) 4.1 framework is used to analyze and design the IT governance. In the first phase, the maturity level is measured to analyze the maturity and gap level of the IT governance in PT. XYZ, i.e. using Plan and Organise (PO) and Acquire and Implement (AI) domains. In the next phase, the priority analysis is conducted. The result of the analysis is considered as essential and critical process take the next analysis, i.e. gap and risk analysis. Afterwards, the IT governance map is designed. The design includes policy, procedure, organization structure, technology recommendation, and processes priority related document template.
\end{abstract}

Keywords: IT Governance, COBIT 4.1, maturity level, plan and organise, acquire and implement

\begin{abstract}
Abstrak
Perusahaan yang menggunakan Teknologi Informasi (TI) sebagai orientasi layanan seharusnya mampu melakukan tata kelola dengan menerapkan tata kelola TI. Penerapan tata kelola TI dapat membantu organisasi dalam membentuk kerangka kerja yang mengarahkan dan memutuskan pemanfaatan TI sesuai kebutuhan yang selaras dengan visi misi, nilai-nilai, strategi, dan budaya organisasi. Terdapat acuan mengenai tata kelola perusahaan yang baik melalui penerapan TI di BUMN, yaitu keputusan Menteri Negara BUMN. Berdasarkan grafik referensi framework tata kelola TI yang tercantum di PER02/ MBU/2013, COBIT 4.1 merupakan framework yang berfokus terhadap hubungan TI dengan bisnis perusahaan. Oleh karena itu, analisis dan perancangan tata kelola TI pada penelitian ini menggunakan framework COBIT (Control Objective for Information and Related Technology) 4.1. Tahap pertama yang dilakukan adalah dengan melakukan penilaian maturity level untuk mengetahui tingkat kedewasaan dan gap pada tata kelola TI PT XYZ domain Plan and Organise (PO) dan Acquire and Implement (AI). Tahap selanjutnya adalah dengan melakukan analisis prioritas. Hasil dari analisis prioritas merupakan proses yang dinilai penting dan kritikal untuk dilakukan analisis gap dan risiko untuk kemudian dilakukan perancangan. Perancangan yang dihasilkan berupa kebijakan, prosedur, struktur organisasi, rekomendasi teknologi, dan template dokumen terkait proses-proses prioritas.
\end{abstract}

Kata Kunci: tata kelola TI, COBIT 4.1, maturity level, plan and organise, acquire and implement

\section{Pendahuluan}

Perkembangan Teknologi Informasi (TI) dan komunikasi kini semakin pesat di berbagai bidang. Hal ini dapat dilihat dari meningkatnya kebutuhan suatu perusahaan akan penerapan TI guna menunjang aktivitas bisnis dan meningkatkan kemampuan kinerja. Penggunaan dan pemanfaatan TI sebaiknya berfungsi dalam penyediaan dan orientasi layanan sehingga perusahaan dapat menyelaras- kannya dengan tujuan bisnis [1]. Perusahaan yang menggunakan TI sebagai orientasi layanan seharusnya mampu melakukan tata kelola dengan menerapkan tata kelola TI (IT governance). Kesuksesan tata kelola perusahaan saat ini mempunyai ketergantungan terhadap perkembangan IT governance yang dilakukan pada sebuah perusahaan [2]. Penerapan IT governance dapat membantu organisasi dalam pembentukan kerangka kerja yang mengarahkan dan memutuskan pemanfaatan TI se- 
suai kebutuhan yang selaras dengan visi misi, nilainilai, strategi dan budaya organisasi.

TI telah menjadi bagian dari perkembangan bisnis di setiap BUMN (Badan Usaha Milik Negara). Terdapat acuan mengenai tata kelola perusahaan yang baik melalui penerapan TI di BUMN yaitu keputusan Menteri Negara BUMN.

Keputusan PER01/MBU/2011 menyatakan bahwa BUMN wajib menerapkan Good Corporate Governance (GCG) secara konsisten dan berkelanjutan dengan tetap memperhatikan ketentuan dan norma yang berlaku serta anggaran dasar BUMN [3]. Adapun prinsip-prinsip GCG berdasarkan PER 01/MBU/2011 yaitu transparansi, akuntabilitas, responsibilitas, independensi, dan kewajaran. Prinsip GCG bertujuan untuk mendorong dan mengoptimalkan BUMN agar perusahaan, dalam hal ini adalah PT XYZ (Persero), memiliki daya saing yang kuat, baik secara nasional maupun internasional secara professional, efisien, dan efektif serta memberdayakan fungsi dan meningkatkan kemandirian Organ Persero. GCG memberi syarat pengelolaan risiko agar mampu menjaga pencapaian tujuan perusahaan dari hal-hal yang memengaruhinya. PT XYZ menerapkan GCG dengan perspektif risiko yang baik dan terintegrasi dalam seluruh area kerja. Hal tersebut diharapkan dapat menghasilkan kinerja yang baik sehingga PT XYZ dapat tumbuh berkelanjutan dalam jangka panjang.

Penerapan prinsip-prinsip GCG dalam pengelolaan TI tersebut memerlukan susunan tata kelola TI yang menjadi bagian integral dari Enterprise Governance agar dapat menjamin pemanfaatan dari implementasi TI. Keputusan PER02/MBU/ 2013 mengarahkan BUMN untuk mengembangkan TI secara terarah dan terukur guna mendukung strategis bisnis serta sejalan dengan tujuan jangka panjang, menengah, dan jangka pendek yang ingin dicapai oleh BUMN [4].

Sebagai perusahaan yang menggunakan TI sebagai pendukung proses bisnis dalam meningkatkan value bisnisnya, maka framework yang tepat untuk diterapkan di PT XYZ adalah COBIT. Berdasarkan grafik referensi framework tata kelola TI yang tercantum di PER02/MBU/2013, menurut guide share Europe, dijelaskan bahwa COBIT merupakan framework yang berfokus terhadap hubungan TI dengan bisnis perusahaan. Versi COBIT yang sesuai dengan PER02/MBU/2013 adalah COBIT 4.1. Hal ini dikarenakan pada versi tersebut COBIT memiliki empat domain yang telah memenuhi kebutuhan BUMN seperti tercantum di PER 02/ MBU/2013.

Berdasarkan langkah-langkah strategis yang menjadi rekomendasi, tahap wawancara dilakukan dengan Kepala Divisi TI untuk mengetahui kondisi yang telah dilakukan sesuai dengan tata kelola yang terstruktur. Berdasarkan hasil wawancara yang telah dilakukan, PT XYZ belum memiliki framework dalam tata kelola TI, namun PT XYZ telah melakukan analisis penerapan tata kelola dengan menggunakan COBIT 4.1 yang tercantum di IT Master Plan tahun 2013-2017. Wawancara dilakukan pula untuk menentukan fokus penelitian yang tidak hanya untuk memenuhi kebutuhan peneliti tetapi memenuhi kebutuhan dari objek penelitian yaitu dari sisi perusahaan.

Berdasarkan hasil analisis tata kelola TI PT XYZ pada tahun 2012, banyak kondisi ideal yang perlu dicapai dalam kesempurnaan proses dan SOP (Standar Operational Procedure) pada domain PO dan AI. Namun, penguatan IT Governance tidak hanya terkait proses, melainkan terdapat enam $\mathrm{ma-}$ turity attribute yang harus dipenuhi dengan melakukan penilaian maturity level.

Enam maturity attribute tersebut antara lain Perencanaan, Kebijakan dan Prosedur, Responsibility and Accountability, Goal Setting and Measurement, Skill and Expertise, Awareness and Communication, dan Tools and Automation. PT XYZ belum melakukan penilaian maturity level berdasarkan enam maturity attribute tersebut. Oleh karena itu, dalam penelitian ini akan dilakukan analisis dan perancangan tata kelola TI dengan menuju target yang akan dicapai sesuai penilaian maturity level dan analisis proses prioritas berdasarkan $\mathrm{CO}$ BIT 4.1 pada domain PO (Plan and Organise) dan AI (Acquire and Implement).

Pada artikel ini terdapat empat bab dalam penulisannya. Bab 1 Pendahuluan menjelaskan latar belakang penelitian dan landasan teori yang digunakan dalam penulisan penelitian dengan mengambil dari beberapa sumber pustaka. Bab 2 Metode menjelaskan tahap yang dilalui dalam melakukan penelitian. Bab 3 Hasil dan Analisis menjelaskan langkah pengumpulan, pengambilan dan analisis data hingga memberikan rekomendasi terkait hasil analisis yang didapat. Sementara itu, Bab 5 Kesimpulan berisi penjelasan secara singkat hasil dari penelitian.

\section{IT Governance}

IT Governance atau Tata Kelola IT didefinisikan sebagai tanggung jawab eksekutif dan dewan direktur, dan terdiri atas kepemimpinan, struktur organisasi serta proses-proses yang memastikan TI perusahaan mendukung dan memperluas obyektif dan strategi organisasi [5]. IT Governance bertujuan untuk mengarahkan upaya TI, serta memastikan performa TI sesuai dengan pemenuhan obyektif TI agar selaras dengan perusahaan dan realisasi keuntungan yang dijanjikan [6]. "ITG is the process by which decisions are made around IT investments, how decisions are made, who makes the decisions, who is held accountabel and how the 


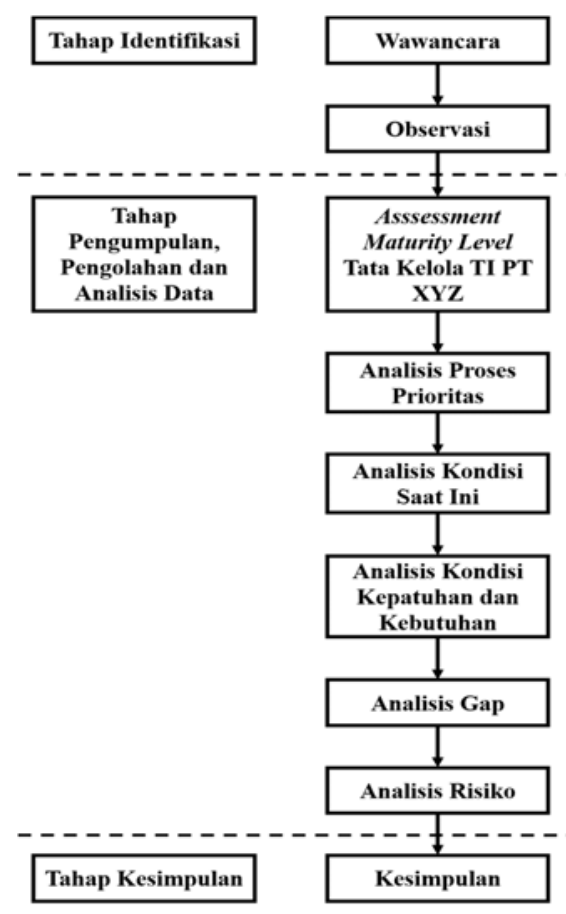

Gambar 2 Metodologi penelitian

results of decisions measured and monitored are all parts of ITG. (IT Governance merupakan sebuah proses dengan keputusan yang dibuat mengenai investasi TI, pembentukan keputusan, pembentuk keputusan, hasil keputusan dan bagaimana keputusan tersebut dapat memonitor seluruh bagian IT Governance)" [7].

\section{Pentingnya Tata Kelola TI}

Tata kelola TI menjadi hal yang penting dan harus diperhatikan demi mencapai tujuan perusahaan. Pentingnya tata kelola TI antara lain adanya perubahan peran TI, dari peran efisiensi ke peran strategik, yang harus ditangani di level korporat. Banyak proyek TI strategik yang penting namun gagal dalam pelaksanaannya karena hanya ditangani oleh teknisi TI. Keputusan TI di Dewan Direksi sering bersifat adhoc atau tidak terencana dengan baik. TI merupakan pendorong utama proses transformasi bisnis yang memberi imbas penting bagi organisasi dalam pencapaian misi, visi dan tujuan strategik. Kesuksesan pelaksanaan TI harus dapat terukur melalui metrik tata kelola TI. [8]

\section{COBIT 4.1}

Menurut IT Governance Institute [5], COBIT 4.1 merupakan kerangka kerja yang memberikan good practice di domain dan proses. Praktik pada COBIT 4.1 akan membantu mengoptimalkan investasi

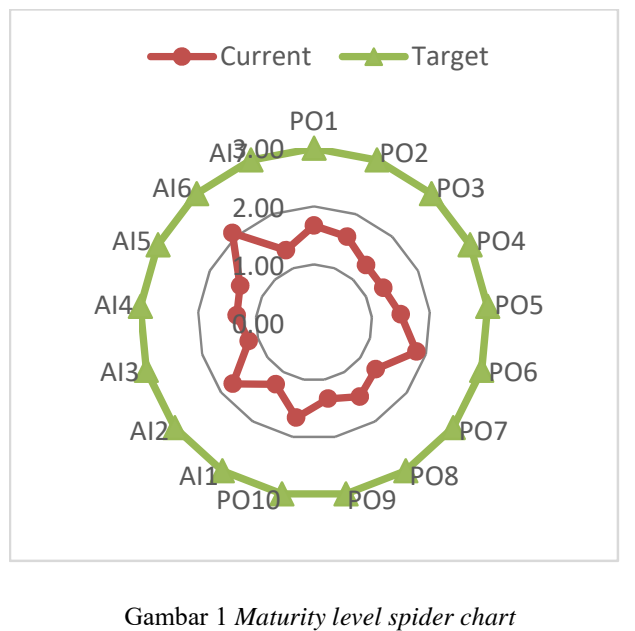

TI, memastikan pelayanan dan memberikan suatu pengukuran. Pada TI, framework COBIT 4.1 memberikan kontribusi pada pemenuhan kebutuhan bisnis, mengidentifikasi sumber daya utama TI dan mendefinisikan tujuan pengendalian manajemen. Framework COBIT 4.1 memiliki 4 domain sebagai proses yang mendukung satu sama lain untuk mengelola TI yaitu Domain Perencanaan dan Organisasi (Plan and Organise), Domain Pengadaan dan Implementasi (Acquire and Implement), Domain Pengantaran dan Dukungan (Deliver and Support) dan Domain Pengawasan dan Evaluasi (Monitor and Evaluate).

\section{Domain PO (Plan and Organise)}

Menurut Supriatna (2011), Domain PO mencakup strategi dan taktik, serta difokuskan pada penentuan arah IT yang dapat memberikan kontribusi terbaik dalam pencapaian tujuan bisnis (business $o b$ jectives) [9] Berikut penjelasan mengenai masingmasing proses di domain PO.

\section{PO1 Define a Strategic IT Plan}

Proses PO1 merupakan proses untuk mendefinisikan rencana strategis yang dibutuhkan dalam mengelola sumber daya TI supaya sejalan dengan strategi bisnis dan prioritas. Rencana strategis ini pada umumnya merupakan perencanaan suatu organisasi atau perusahaan secara tertulis yang akan menjadi panduan dalam mencapai tujuan organisasi.

PO2 Define the Information Architecture Proses PO2 merupakan proses untuk mendefinisikan fungsi suatu sistem informasi dalam menciptakan informasi bisnis dan sistem yang tepat untuk mengoptimalkan penggunaan informasi di suatu organisasi atau perusahaan. Proses ini dapat meningkatkan kualitas pengambilan keputusan ma- 
najemen dengan memastikan informasi tersebut aman dan sesuai strategi bisnis.

\section{PO3 Determine Technological Direction}

Proses PO3 merupakan proses untuk mendefinisikan penentuan arah teknologi untuk mendukung bisnis yang dapat dilakukan berdasarkan layanan informasi. Penentuan arah teknologi membutuhkan perencanaan infrastruktur dan arsitektur sebagai pengelola produk, layanan dan mekanisme teknologi.

PO4 Define the IT Process, Organisation and Relationship

Proses PO4 merupakan proses yang mendefinisikan persyaratan untuk staf, keterampilan, tanggung jawab dari suatu organisasi. Proses TI menjamin transparansi, kontrol, dan manajemen bisnis.

\section{PO5 Manage the IT Investment}

Proses PO5 merupakan proses yang mendefinisikan pengelolaan program investasi TI yang meliputi biaya, manfaat, prioritas dalam anggaran, dan manajemen terhadap anggaran.

PO6 Communicate Management Aims and Direction

Proses PO6 mendefinisikan mengenai pengembangan framework sebagai pengendali TI perusahaan yang dikelola manajemen. Komunikasi dijalankan sebagai implementasi untuk mengartikulasikan misi, tujuan, kebijakan, dan prosedur. Komunikasi mendukung pencapaian tujuan TI dan memastikan kesadaran dan pemahaman mengenai bisnis, risiko TI, tujuan, dan arah.

TABEL 1

ASSESSMENT MATURITY LEVEL PO DAN AI

\begin{tabular}{lll}
\multicolumn{3}{c}{ ASSESSMENT MATURITY LEVEL PO DAN AI } \\
\hline \multirow{2}{*}{ Proses } & \multicolumn{2}{c}{ Tingkat Kematangan } \\
& Maturity Level As-is & Maturity Level To-be \\
\hline PO1 & 1.67 & 3.00 \\
PO2 & 1.58 & 3.00 \\
PO3 & 1.33 & 3.00 \\
PO4 & 1.33 & 3.00 \\
PO5 & 1.50 & 3.00 \\
PO6 & 1.83 & 3.00 \\
PO7 & 1.33 & 3.00 \\
PO8 & 1.50 & 3.00 \\
PO9 & 1.33 & 3.00 \\
PO10 & 1.67 & 3.00 \\
AI1 & 1.25 & 3.00 \\
AI2 & 1.75 & 3.00 \\
AI3 & 1.17 & 3.00 \\
AI4 & 1.33 & 3.00 \\
AI5 & 1.42 & 3.00 \\
AI6 & 2.08 & 3.00 \\
AI7 & 1.33 & 3.00 \\
& &
\end{tabular}

PO7 Manage IT Human Resources

Proses PO7 mendefinisikan mengenai pencapaian layanan TI menjadi suatu bisnis. Pencapaian tersebut didapatkan berdasarkan pengelolaan sumber daya melalui pemilihan, pelatihan, evaluasi kinerja, promosi dan pemberhentian kerja.

PO8 Manage Quality

Proses PO8 mendefinisikan mengenai proses yang mengelola kualitas TI dengan memelihara pengembangan dan akuisisi proses serta standar yang terbukti. Pelaksanaan dan pemeliharaannya dilakukan dengan memberikan kualitas persyaratan, prosedur dan kebijakan.

PO9 Assess and Manage IT Risk

Manajemen risiko TI sebaiknya dilakukan dan dipelihara. Risiko merupakan suatu dampak yang terjadi dari suatu peristiwa yang tidak direncanakan. Karenanya, proses ini dilakukan untuk mengidentifikasi, menganalisis dan menilai suatu risiko, untuk kemudian diberikan tindakan.

PO10 Manage Projects

PO10 mendefinisikan manajemen framework suatu proyek sebagai pengelolaan semua proyek TI. Framework menjamin prioritas serta koordinasi dari semua proyek yang mencakup rencana, penugasan sumber daya, definisi, persetujuan pengguna, pendekatan, rencana uji formal, pengujian, dan pascapelaksanaan ulasan.

\section{Domain AI (Acquire and Implement)}

Domain ini mewujudkan strategi TI dan memberikan solusi TI yang perlu diidentifikasi, dikembangkan atau diperoleh serta diimplementasikan

TABEL 2

KONVERSI NILAI TUJUAN BISNIS

\begin{tabular}{llll}
\hline $\begin{array}{c}\text { Perspektif } \\
\text { Kinerja }\end{array}$ & $\begin{array}{c}\text { Tujuan } \\
\text { Bisnis }\end{array}$ & Nilai & $\begin{array}{c}\text { Rata-rata nilai } \\
\text { per perspektif }\end{array}$ \\
\hline Financial & TB1 & 8.5 & 6.1 \\
& TB2 & 4.9 & \\
Customer & TB3 & 4.9 & \\
& TB4 & 7.9 & 7.8 \\
& TB5 & 7.7 & \\
& TB6 & 8.7 & \\
& TB7 & 3.3 & \\
Internal & TB8 & 9.7 & \\
& TB9 & 9.2 & \\
& TB10 & 10.0 & 7.4 \\
& TB11 & 3.8 & \\
& TB12 & 7.4 & \\
Learning and & TB13 & 8.5 & \\
Growth & TB16 & 9.4 & \\
\hline & TB17 & 1.0 & \\
\hline
\end{tabular}


dan diintegrasikan dalam proses bisnis. Perubahan dan pemeliharaan sistem juga terdapat dalam domain ini untuk memastikan solusi untuk memenuhi tujuan bisnis. Berikut penjelasan mengenai proses di domain $\mathrm{AI}$ :

\section{AI1 Identify Automated Solutions}

Proses AI1 mendefinisikan perlunya analisis untuk memastikan bahwa persyaratan bisnis terpenuhi dalam pendekatan yang efektif dan efisien. Menurut Thijin [10], Proses ini meliputi definisi kebutuhan, pertimbangan sumber alternatif, review kelayakan teknologi dan ekonomi, pelaksanaan analisis risiko dan analisis biaya-manfaat, dan kesimpulan atas keputusan akhir untuk 'membuat' atau 'membeli'.

AI2 Acquire and Maintain Application Software Proses AI2 mendefinisikan bahwa aplikasi yang tersedia harus sesuai dengan kebutuhan bisnis. Aplikasi yang sesuai dengan kebutuhan bisnis berdasarkan desain aplikasi, kontrol aplikasi, persyaratan keamanan, pengembangan, dan konfigurasi sesuai dengan standar.

\section{AI3 Acquire and Maintain Technology Infrastruc-} ture

Infrastruktur teknologi dalam suatu organisasi perlu dilakukan akuisisi, implementasi dan pembaruan yang telah disepakati sesuai dengan strategi teknologi dan penyedia pengembangan serta uji lingkungan.

\section{AI4 Enable Operation and Use}

Proses AI4 mendefinisikan pengetahuan organisasi terhadap sistem baru yang tersedia. Penggunaan sistem baru yang tersedia membutuhkan dokumentasi untuk memastikan penggunaan, pengoperasian aplikasi dan infrastruktur dilakukan dengan tepat.

TABEL 3

\begin{tabular}{clll}
\multicolumn{4}{c}{ KonVERS NILAI TUJUAN TI } \\
\hline $\begin{array}{c}\text { Tujuan } \\
\text { TI }\end{array}$ & Nilai & Tujuan TI & Nilai \\
\hline TTI1 & 3.8 & TTI15 & 8.7 \\
TTI2 & 7.0 & TTI16 & 4.9 \\
TTI3 & 7.9 & TTI17 & 4.9 \\
TTI4 & 9.2 & TTI18 & 6.2 \\
TTI5 & 6.2 & TTI19 & 7.2 \\
TTI6 & 7.2 & TTI20 & 6.2 \\
TTI7 & 8.4 & TTI21 & 7.0 \\
TTI8 & 7.9 & TTI22 & 3.8 \\
TTI9 & 1.0 & TTI23 & 7.0 \\
TTI10 & 9.2 & TTI24 & 7.9 \\
TTI11 & 8.1 & TTI25 & 9.2 \\
TTI12 & 9.2 & TTI26 & 6.2 \\
TTI13 & 7.4 & TTI27 & 7.2 \\
TT114 & 4.9 & TTI28 & 8.7 \\
\hline
\end{tabular}

\section{AI5 Procure IT Resources}

Proses AI5 mendefinisikan bahwa sumber daya TI antara lain anggota, software, hardware dan layanan membutuhkan definisi dan penegakan prosedur pengadaan, pengaturan kontrak dan akuisisi. Hal ini diperlukan agar organisasi memiliki dokumen mengenai sumber daya TI dan keperluannya.

\section{AI6 Manage Changes}

Perubahan dapat terjadi di suatu organisasi atau perusahaan yang berkaitan dengan TI dan bisnis. Perubahan dapat termasuk pemeliharaan darurat atau perubahan yang berkaitan dengan infrastruktur dan aplikasi. Perubahan dikelola secara terkendali agar perubahan dapat ditangani dengan efektif dan efisien baik bagi perubahan yang baru terjadi atau perubahan yang dapat terjadi di masa mendatang.

AI7 Install and Accredit Solutions and Changes Proses AI7 mendefinisikan mengenai solusi dan perubahan yang terjadi setelah suatu pengembangan aplikasi selesai dilakukan. Solusi tersebut antara lain dilakukannya pengujian yang berhubungan dengan uji data, instruksi, perencanaan, dan evaluasi.

\section{Maturity Level}

Maturity model atau model kematangan digunakan untuk mengukur tingkat kedewasaan tata kelola TI. Pengukuran dilakukan untuk mengetahui kondisi saat ini, teknologi perusahaan atau tingkatan kematangan saat ini, dan tingkatan yang ingin dicapai perusahaan. Model ini memetakan tingkat kematangan tata kelola TI dengan tingkat yang memiliki rentang dari angka 0 (non existent) hingga 5 (optimized). Setiap tingkat kematangan memiliki penjelasan masing-masing yang dapat menggambarkan kondisi TI perusahaan.

TABEL 4

\begin{tabular}{lll}
\multicolumn{3}{c}{ KONVERSI NILAI PROSES TI } \\
\hline Proses & Nilai Per Domain & $\begin{array}{c}\text { Nilai Per } \\
\text { Proses }\end{array}$ \\
\hline PO1 & 6 & 5.4 \\
PO2 & & 6.8 \\
PO3 & & 6.1 \\
PO4 & & 5.7 \\
PO5 & & 7.8 \\
PO6 & & 7.2 \\
PO7 & & 3.6 \\
PO8 & & 7.6 \\
PO9 & & 4.9 \\
PO10 & 7 & 5.7 \\
AI1 & 5.5 \\
AI2 & & 7.8 \\
AI3 & & 5.9 \\
AI4 & & 8.0 \\
AI5 & & 5.7 \\
AI6 & & 7.0 \\
AI7 & 6.9 \\
\hline
\end{tabular}


TABEL 5

JUSTIFIKASI PROSES PRIORITAS

\begin{tabular}{|c|c|}
\hline Proses Prioritas & Justifikasi \\
\hline $\begin{array}{l}\text { PO5 Manage The IT } \\
\text { investment }\end{array}$ & $\begin{array}{l}\text { Meningkatkan kinerja proses Manage The IT Investment secara terstruktur dan melengkapi doku- } \\
\text { mentasi terkait pengelolaan investasi yang berfokus dalam menganalisis prioritas anggaran } \\
\text { kebutuhan TI serta proses pengajuan anggaran ke Bagian Anggaran. }\end{array}$ \\
\hline PO8 Manage Quality & $\begin{array}{l}\text { Meningkatkan kinerja proses Manage Quality untuk memaksimalkan perkembangan TI di PT XYZ } \\
\text { yang menjadi fokus utama Divisi TI serta melengkapi dokumentasi terkait proses pengelolaan } \\
\text { kualitas TI supaya proses didukung oleh dokumen-dokumen yang tepat sesuai dengan aturan COBIT } \\
\text { 4.1. }\end{array}$ \\
\hline $\begin{array}{l}\text { AI2 Acquire and } \\
\text { Maintain Application } \\
\text { Software }\end{array}$ & $\begin{array}{l}\text { Meningkatkan kinerja proses Acquire and maintain application software untuk mendukung proses } \\
\text { pengembangan aplikasi, melengkapi kekurangan langkah proses yang ada pada kondisi proses saat } \\
\text { ini serta menyesuaikan dokumentasi sesuai dengan aturan COBIT } 4.1 . .\end{array}$ \\
\hline $\begin{array}{l}\text { AI4 Enable } \\
\text { Operation and Use }\end{array}$ & $\begin{array}{l}\text { Meningkatkan kinerja proses Enable ope-ration and use untuk memberi hasil yang maksimal pada } \\
\text { layanan TI dengan memastikan penggunaan, pengoperasian aplikasi dan infrastruktur dilakukan } \\
\text { dengan tepat. Memeberi rekomendasi prosedur baku dan kebijakan mengenai operasi dan } \\
\text { penggunaan aplikasi secara umum yang belum terdokumentasi. }\end{array}$ \\
\hline $\begin{array}{l}\text { AI7 Install and } \\
\text { Accredit Solutions } \\
\text { and Changes }\end{array}$ & $\begin{array}{l}\text { Meningkatkan kinerja proses Install and accredit solutions and changes sehingga proses instalasi } \\
\text { dan akreditasi suatu aplikasi yang akan di setelah suatu pengembangan aplikasi selesai dilakukan } \\
\text { dapat berjalan dengan tepat. Memberikan rekomendasi langkah proses yang belum terdokumentasi. }\end{array}$ \\
\hline
\end{tabular}

\section{Analisis Gap}

Analisis Gap merupakan suatu metode untuk membantu suatu lembaga membandingkan performansi actual dengan performansi potensi [11]. Analisis Kesenjangan merupakan identifikasi proses yang tidak terdefinisi, yang diperlukan untuk mencapai suatu tujuan. Proses yang tidak terdefinisi tersebut menjadi alat untuk merencanakan hal-hal yang perlu dilakukan untuk menutupi kesenjangan antara kondisi saat ini dan target yang akan dicapai.

\section{Analisis Risiko}

Analisis risiko merupakan proses untuk memahami sifat risiko dan menentukan tingkat prioritas risiko [12]. Analisis risiko merupakan sebuah sistematika yang didapat untuk menentukan frekuensi suatu kejadian tertentu dapat terjadi dan besarnya konsekuensi tersebut berdasarkan gap dari kondisi kebutuhan dan kondisi saat ini.

\section{Metode}

Metode penelitian dijelaskan pada Gambar 1 dengan rincian tahapannya sebagai berikut.

\section{Tahap Identifikasi}

Pada tahap identifikasi dilakukan wawancara dengan Kepala Divisi Teknologi Informasi PT XYZ terkait kondisi tata kelola TI saat ini yang sedang terjadi di PT XYZ dan proses yang berjalan terkait dengan framework COBIT 4.1 sebagai sebuah kepatuhan yang harus digunakan dalam pengelolaan tata kelola TI oleh BUMN. Selain itu wawancara dilakukan untuk menentukan fokus penelitian yang tidak hanya untuk memenuhi kebutuhan peneliti, tetapi memenuhi kebutuhan dari objek penelitian yaitu dari sisi perusahaan. Kemudian, setelah wawancara, dilakukan observasi untuk mengetahui secara langsung terkait dengan isu-isu yang telah diketahui pada saat wawancara. Berdasarkan tahap identifikasi awal, didapatkan kesimpulan bahwa kebutuhan perusahaan yaitu meningkatkan tata kelola TI pada tahap dan proses perencanaan serta implementasi solusi TI yang dibutuhkan. Hal ini sesuai dengan menggunakan framework COBIT 4.1 pada domain Plan and Organise (PO) dan Acquire and Implement (AI).

\section{Tahap Pengumpulan, Pengolahan dan Analisis Data}

Pada tahap ini dilakukan assessment maturity level tata kelola TI PT XYZ, assessment dilakukan dengan wawancara kepada pihak terkait dengan proses yang ada pada domain PO dan AI. Kemudian dilakukan analisis prioritas dengan memetakan sasaran perusahaan dengan business goals, IT goals dan IT process COBIT 4.1. Kemudian setelah prioritas proses didapatkan, dilakukan Analisis Kondisi Saat Ini dan Analisis Kondisi Kepatuhan dan Kebutuhan TI. Kepatuhan TI berbicara mengenai kewajiban dari PT XYZ sebagai BUMN untuk memenuhi PER01/MBU/2011 dan PER02/ MBU/2013 untuk mencapai tingkat kematangan pada nilai 3 di tahun 2018. Sedangkan kebutuhan TI berbicara mengenai RJPP (Rencana Jangka Panjang Perusahaan) yang belum terealisasikan sehingga menjadi suatu kebutuhan yang apabila kebutuhan tersebut dipenuhi dapat mendukung pencapaian tujuan bisnis PT XYZ. Hasil dari analisis tersebut dilanjutkan dengan analisis gap dan ana- 
TABEL 6

KONDISI SAAT INI PT XYZ

\begin{tabular}{|c|c|}
\hline Proses & Kondisi Saat Ini \\
\hline $\begin{array}{l}\text { PO5 Manage The } \\
\text { IT investment }\end{array}$ & $\begin{array}{l}\text { Entitas struktur yang bertanggung jawab atas pelaksanaan proses ini tidak hanya terpusat di Divisi TI } \\
\text { saja, proses juga melibatkan Divisi Anggaran. Pengajuan investasi TI dilakukan oleh divisi TI } \\
\text { berdasarkan identifikasi dari RJPP, kebutuhan user dan IT Master Plan. Pengajuan investasi TI diteruskan } \\
\text { ke Divisi Anggaran dan persetujuan dilakukan oleh pihak Direksi. Tool yang digunakan untuk pengajuan } \\
\text { adalah BioAnggaran. Dokumen acuan yang digunakan adalah IT Master Plan dan RJPP, laporan terkait } \\
\text { aktifitas proses belum terdokumentasi. }\end{array}$ \\
\hline PO8 Manage & Entitas struktur yang bertanggung jawab atas pelaksanaan proses ini adalah Bagian Pengembangan \\
\hline Quality & $\begin{array}{l}\text { Sistem. Sistem Manajemen Kualitas TI di PT XYZ berjalan dengan adanya proses validasi yang } \\
\text { menjamin kualitas instalasi, operasional dan kinerja. Prosedur yang digunakan pada proses ini masih } \\
\text { menggunakan prosedur yang sama dengan pengembangan perangkat lunak komputer dengan beberapa } \\
\text { aturan dalam prosedur tersebut yaitu terkait dengan validasi Installation Qualification, Operational } \\
\text { Qualification, Performance Qualification. Prosedur tersediri untuk manajemen kualitas belum } \\
\text { terdefinisi. Tool yang digunakan adalah Software terkait yang dilakukan validasi, Microsoft Office } \\
\text { Outlook untuk pengiriman email dan Microsoft Office. }\end{array}$ \\
\hline AI2 Acquire and & Entitas struktur yang bertanggung jawab atas pelaksanaan proses ini adalah Bagian Pengembangan \\
\hline Maintain & Sistem. Proses pemerolehan dan pemeliharaan aplikasi software di PT XYZ yaitu dengan melakukan \\
\hline Application & analisis terlebih dahulu terhadap kesesuaian aplikasi dengan kebutuhan bisnis dan melakukan \\
\hline Software & $\begin{array}{l}\text { tahap perancangan aplikasi. Pemeliharaan terus dilakukan selama aplikasi masih aktif digunakan di PT } \\
\text { XYZ dengan menerima feedback dari user dan terus melakukan perbaikan. Prosedur yang digunakan } \\
\text { adalah Prosedur Pengembangan Perangkat Lunak. Tools yang digunakan adalah aplikasi untuk } \\
\text { mengembangkan aplikasi, namun belum terdapat tools yang digunakan untuk pemeliharaan aplikasi. }\end{array}$ \\
\hline AI4 Enable & Entitas struktur yang bertanggung jawab atas pelaksanaan proses ini adalah Bagian Pengembangan \\
\hline $\begin{array}{l}\text { Operation and } \\
\text { Use }\end{array}$ & $\begin{array}{l}\text { Sistem. Proses dalam memberikan pengetahuan atau pelatihan kepada organisasi mengenai sistem baru } \\
\text { dilakukan dengan sosialisasi secara formal. Sosialisasi dilakukan kepada karyawan atau user dari sistem } \\
\text { baru, dan sosialisasi dilakukan oleh tim software development. Setelah dilakukan sosialisasi, tim } \\
\text { development dapat menerima feedback dari user dengan memberikan dokumen change request atau } \\
\text { dengan mengirimkan email. Prosedur pada penggunaan aplikasi tertentu sudah terdefinisi, prosedur } \\
\text { berisikan penjelasan mengenai fungsi-fungsi yang ada di aplikasi. }\end{array}$ \\
\hline AI7 Insta & Entitas struktur yang bertanggung jawab atas pelaksanaan proses ini adalah Bagian Pengembangan \\
\hline Accredit & Sistem. Pada proses ini, setelah melakukan pengembangan aplikasi, terdapat validasi pada instalasi dan \\
\hline Solutions & pengujian aplikasi yang terintegrasi. Pengujian dilakukan oleh Bagian Pengembangan Sistem dan \\
\hline Changes & $\begin{array}{l}\text { melibatkan user. Proses pengujian yang dilakukan sebelum instalasi belum terdokumentasi dan prosedur } \\
\text { yang ada masih tergabung dengan Prosedur Baku Pengembangann Perangkat Lunak. Penjelasan } \\
\text { mengenai langkah-langkah pengujian tidak tertera secara detail. }\end{array}$ \\
\hline
\end{tabular}

lisis risiko pada proses prioritas yang menjelaskan kemungkinan dampak yang terjadi akibat gap yang teridentifikasi dan penjelasan respond yang diberikan untuk mengatasi kemungkinan resiko.

\section{Tahap Kesimpulan}

Pada tahap akhir ini dibuat kesimpulan dari keseluruhan tahap dan hasil penelitian.

\section{Hasil dan Analisis}

\section{Assessment Maturity Level}

Assessment maturity level dilakukan dengan proses wawancara mengenai proses PO dan AI framework COBIT 4.1 dengan narasumber object penelitian yaitu PT XYZ. Narasumber wawancara ditentukan berdasarkan posisi, jabatan dan tanggung jawab yang berkaitan dengan proses-proses di PO dan AI. Dalam melakukan assessment maturity level terdapat enam maturity attribute yang menentukan nilai masing-masing proses, enam atribut tersebut antara lain: Kebijakan, Perencanaan dan Prosedur (Policies, Plans, and Procedures); Tanggung Jawab dan Akuntabilitas (Responsibility and Accountability); Penetapan dan Pengukuran Tujuan
(Goal Setting and Measurement); Keterampilan dan Keahlian (Skill and Expertise); Kesadaran dan Komunikasi (Awereness \& Communication); dan Alat dan Otomatisasi (Tools and Automation). Setiap atribut akan mempunyai nilai dari level nol (0) sampai lima (5) yang kemudian nilai tersebut akan dihitung rata-ratanya untuk mendapatkan maturity level pada satu proses.

Maturity Level didapat untuk mengetahui kematangan proses dan gap yang nantinya akan teridentifikasi berdasarkan analisis kondisi saat ini dan analisis kondisi kepatuhan dan kebutuhan TI. Hasil assessment maturity level dijelaskan pada Tabel 1. Hasil maturity level Tata Kelola TI PT XYZ pada domain PO dan AI dalam bentuk spider chart dapat dilihat pada Gambar 2.

\section{Analisis Proses Prioritas}

Analisis prioritas proses dilakukan untuk menentukan proses yang diutamakan untuk diberikan solusi dan perancangan dokumen yang mendukung proses sehingga dapat meningkatkan maturity level tata kelola TI perusahaan. Analisis dilakukan dengan pemetaan yang melibatkan sasaran perusahaan yang didapat dari RJPP PT XYZ serta tujuan bisnis perusahaan menurut framework COBIT 4.1. 
TABEL 7

REKOMENDASI DOKUMEN

\begin{tabular}{|c|c|}
\hline Aspek & Rekomendasi \\
\hline \multirow[t]{19}{*}{ Process } & Kebijakan TI \\
\hline & Prosedur Baku Manajemen Investasi TI \\
\hline & Pedoman Manajemen Investasi TI \\
\hline & Laporan Cost-Benefit \\
\hline & Dokumen IT Budget \\
\hline & Prosedur Baku Manajemen Kualitas TI \\
\hline & Pedoman Manajemen Kualitas TI \\
\hline & Dokumen Quality Standard \\
\hline & Prosedur Baku Pengembangan dan Pemeliharaan Perangkat Lunak \\
\hline & Pedoman Pengembangan dan Pemeliharaan Perangkat Lunak \\
\hline & Dokumen Application Security Control Specification \\
\hline & Prosedur Baku Operasi dan Penggunaan Aplikasi \\
\hline & Pedoman Operasi dan Penggunaan Aplikasi \\
\hline & Prosedur Baku Instalasi dan Akreditasi Solusi serta Perubahan \\
\hline & Pedoman Instalasi dan Akreditasi Solusi serta Perubahan \\
\hline & Formulir Data Configuration Items \\
\hline & Formulir Data Masalah yang Terdeteksi \\
\hline & Post-Implementation Review \\
\hline & Dokumen Software Release \\
\hline \multirow[t]{2}{*}{ People } & Rekomendasi Struktur Organisasi \\
\hline & Rekomendasi Peran, Tanggung Jawab dan Kebutuhan Kompetensi \\
\hline \multirow[t]{3}{*}{ Technology } & Rekomendasi Aplikasi untuk Proses PO8 \\
\hline & Rekomendasi Aplikasi untuk Proses AI4 \\
\hline & Rekomendasi Aplikasi untuk Proses AI7 \\
\hline
\end{tabular}

Pada tujuan bisnis COBIT 4.1 dijelaskan dalam perspektif kinerjanya, yaitu financial, customer, internal, dan learning. Proses pemetaan yang dilakukan bertujuan untuk menyimpulkan proses yang merupakan prioritas perusahaan berdasarkan pemetaan pada framework COBIT 4.1.

\section{Hasil Pemetaan Sasaran Perusahaan}

Hasil pemetaan sasaran perusahaan dengan tujuan bisnis COBIT 4.1 ditunjukkan oleh Tabel 2. Hasil pemetaan sasaran perusahaan dengan tujuan TI COBIT 4.1 ditunjukkan oleh Tabel 3. Adapun hasil pemetaan sasaran perusahaan dengan proses domain PO dan AI COBIT 4.1 ditunjukkan oleh Tabel 4.

Proses yang menjadi prioritas merupakan proses yang memiliki nilai yang paling besar berdasarkan pemetaan tujuan bisnis dan tujuan TI pada COBIT 4.1. Langkah selanjutnya setelah melakukan pemetaan proses bisnis dan TI serta mendapatkan nilai yang menunjukkan kepentingan proses adalah mengkomunikasikannya dalam Forum Group Discussion (FGD) bersama Kepala Divisi TI, Ahli Madya IT Governance \& Police, Kepala Bagian System Development dan Kepala Bagian Infrastruktur dan Operasi. Kegiatan FGD menghasilkan persetujuan mengenai pemetaan proses bisnis dan TI serta nilai kepentingan proses. Diskusi tersebut menghasilkan kesepakatan bahwa jumlah re- komendasi proses untuk perancangan adalah 5 (lima) proses yang terdiri dari proses PO5 Manage the IT investment, PO8 Manage quality, AI2 Acquire and maintain application software, AI4 Enable operation and use, dan AI7 Install and accreditsolutions and changes.

Pada proses yang tidak terpilih, menjelaskan bahwa proses-proses tersebut belum menjadi prioritas Divisi TI PT XYZ dalam menyelaraskan tujuan TI dengan tujuan Bisnis. Hal ini dapat dilihat pada Tabel 4 kolom Nilai Per Proses menunjukkan angka-angka prioritas dari 1 (kurang prioritas) sampai 10 (prioritas). Sementara itu, nilai maturity level yang rendah menunjukkan Divisi TI belum mapan dalam menjalankan proses. Sehingga apabila maturity level didapatkan rendah dan belum prioritas, maka Divisi TI memilih untuk memprioritaskan maturity level, baik rendah maupun tinggi, namun dinyatakan prioritas pada hasil akhir pemetaan. Ini bertujuan untuk memaksimalkan proses sehingga mencapai nilai 3. Penjelasan proses prioritas dan justifikasi setiap proses termuat pada Tabel 5.

\section{Analisis Kondisi Saat Ini}

Kondisi Saat Ini perusahaan merupakan kondisi yang sedang terjadi di perusahaan. Kondisi Saat Ini berdasarkan proses domain COBIT 4.1 telah didapatkan dengan melakukan assessment maturity 
level tata kelola TI. Kondisi Saat Ini diketahui untuk dapat menentukan kesenjangan yang ada di perusahaan setelah mengetahui target yang ingin dicapai perusahaan. Penjelasan mengenai Kondisi Saat Ini pada proses yang telah menjadi prioritas dijabarkan pada Tabel 6.

\section{Analisis Kondisi Kepatuhan dan Kebutuhan TI}

Analisis Kondisi Kepatuhan dan Kebutuhan TI merupakan analisis yang dilakukan untuk mengetahui rekomendasi yang tepat sesuai dengan kesenjangan yang ada berdasarkan hasil analisis gap dan risiko. Kondisi kepatuhan TI berbicara mengenai kewajiban dari PT XYZ untuk memenuhi PER01/MBU/ 2011 dan PER02/MBU/2013 untuk mencapai tingkat kematangan rata rata minimal 3 pada tahun 2018. Kebutuhan TI berbicara mengenai amanat dari RJPP mengenai kebutuhan dukungan TI ke depan untuk mendukung pencapaian tujuan bisnis PT XYZ.

Analisis Kondisi Kepatuhan dan Kebutuhan TI dilakukan dengan melihat 3 aspek pada framework COBIT 4.1 yaitu people, technology dan process. Masing-masing proses yang menjadi prioritas pada domain PO dan AI memerlukan pencapaian 3 aspek pada framework COBIT 4.1 tersebut. Berikut adalah analisis 3 aspek utama pada proses prioritas domain PO dan AI COBIT 4.1.

\begin{tabular}{|c|c|c|c|c|}
\hline \multirow{2}{*}{$\begin{array}{c}\text { Pro- } \\
\text { ses }\end{array}$} & \multicolumn{3}{|c|}{ Nilai } & \multirow[b]{2}{*}{ Analisis Gap } \\
\hline & $\begin{array}{c}\text { Eksis } \\
\text { ting }\end{array}$ & $\begin{array}{l}\text { Tar- } \\
\text { get }\end{array}$ & Gap & \\
\hline PO5 & 1.50 & 3.00 & 1.50 & $\begin{array}{l}\text { Belum memiliki dokumen } \\
\text { SOP, indikator kinerja, } \\
\text { dan dokumen yang dapat } \\
\text { menjadi acuan dalam } \\
\text { menentukan prioritas } \\
\text { investasi TI. Entitas yang } \\
\text { melakukan proses tidak } \\
\text { terpusat di Divisi TI saja. }\end{array}$ \\
\hline PO8 & 1.50 & 3.00 & 1.50 & $\begin{array}{l}\text { Belum memiliki dokumen } \\
\text { SOP, indikator kinerja dan } \\
\text { belum memiliki dokumen } \\
\text { pendukung proses. }\end{array}$ \\
\hline $\mathrm{AI} 2$ & 1.75 & 3.00 & 1.17 & $\begin{array}{l}\text { Belum memiliki dokumen } \\
\text { SOP, indikator kinerja dan } \\
\text { belum memiliki dokumen } \\
\text { pendukung terkait proses. }\end{array}$ \\
\hline AI4 & 1.33 & 3.00 & 1.67 & $\begin{array}{l}\text { Belum memiliki dokumen } \\
\text { SOP, indikator kinerja } \\
\text { serta dokumen terkait }\end{array}$ \\
\hline & & & & $\begin{array}{l}\text { laporan kebutuhan } \\
\text { training dan laporan } \\
\text { pelaksanaan training. }\end{array}$ \\
\hline AI7 & 1.33 & 3.00 & 1.67 & $\begin{array}{l}\text { Belum memiliki dokumen } \\
\text { SOP, indikator kinerja } \\
\text { serta dokumen terkait } \\
\text { laporan eror yang terjadi, } \\
\text { review implementasi, dan } \\
\text { rencana sofrware release } \\
\text { dan distribusi. }\end{array}$ \\
\hline
\end{tabular}

People

Peningkatan sumber daya manusia dan organisasi pada penelitian ini adalah dengan memberikan rekomendasi berupa struktur organisasi sesuai dengan proses prioritas, serta deskripsi kerja dari setiap perancangan proses prioritas bagi PT XYZ.

\section{Technology}

Pada poses prioritas secara keseluruhan, rekomendasi yang diberikan untuk aspek teknologi perusahaan adalah dengan menggunakan aplikasi yang dapat terintegrasi seperti dalam penyimpanan data yang dapat ter-update dan terintegrasi sehingga dapat membantu kinerja proses.

\section{Process}

\section{PO5 - Manage the IT Investment}

Kondisi Kepatuhan dan Kebutuhan TI yang seharusnya dimiliki proses ini adalah dengan memiliki dokumen SOP Manage The IT Investment dan dokumentasi laporan terkait proses untuk meningkatkan kinerja divisi dalam mengelola proyek TI PT XYZ.

\section{PO8 - Manage Quality}

Kondisi Kepatuhan dan Kebutuhan TI yang seharusnya dimiliki proses ini adalah dengan memiliki dokumen SOP Manage Quality yang terdokumentasi dengan baik serta dokumentasi laporan terkait proses untuk meningkatkan kinerja divisi dalam mengelola kualitas TI PT XYZ.

AI2 - Acquire and maintain application software Kondisi Kepatuhan dan Kebutuhan TI yang seharusnya dimiliki proses ini adalah dengan memiliki dokumen SOP Acquire and maintain application

TABEL 9

PARAMETER TINGKAT RISIKO

\begin{tabular}{|c|c|c|}
\hline Kategori & Probability & Dampak \\
\hline Low (L) & $\begin{array}{l}1 \text { kali dalam } \\
5 \text { tahun }\end{array}$ & $\begin{array}{lr}\text { Risiko } & \text { tidak } \\
\text { menyebabkan dampak } \\
\text { yang parah dan pe- } \\
\text { nanganan tidak harus } \\
\text { segera dilakukan. }\end{array}$ \\
\hline $\begin{array}{l}\text { Medium } \\
\text { (M) }\end{array}$ & $\begin{array}{l}1 \text { kali dalam } \\
1 \text { tahun }\end{array}$ & $\begin{array}{lr}\text { Risiko } & \text { tidak } \\
\text { menyebabkan dampak } \\
\text { yang parah, namun } \\
\text { penanganan harus segera } \\
\text { di-lakukan. }\end{array}$ \\
\hline $\operatorname{High}(\mathrm{H})$ & $\begin{array}{l}>1 \text { kali } \\
\text { dalam } 1 \\
\text { bulan }\end{array}$ & $\begin{array}{lr}\text { Terdapat risiko yang } \\
\text { dise-babkan oleh } \\
\text { terganggunya fungsi } \\
\text { layanan sehingga me- } \\
\text { nyebabkan masalah yang } \\
\text { berulang rarena } \\
\text { kerusakan atau aktifitas } \\
\text { tidak dapat be-rjalan } \\
\text { sehingga menghambat } \\
\text { aktifitas lainnya. } \\
\begin{array}{l}\text { Penangan-an har has } \\
\text { segera dilakukan. }\end{array}\end{array}$ \\
\hline
\end{tabular}


TABEL 10

ANALISIS RISIKO

\begin{tabular}{|c|c|c|c|}
\hline Proses & Dampak Risiko & Probability & Respond \\
\hline PO5 & $\begin{array}{l}\text { Menghambat pemenuhan kebutuhan kare- } \\
\text { na proses membutuhkan waktu yang lama } \\
\text { dan dapat terjadinya kesalahan dalam me- } \\
\text { nentukan prioritas investasi. }\end{array}$ & $\bar{M}$ & $\begin{array}{l}\text { Membuat Prosedur dan Pedoman terkait Manage The IT } \\
\text { Investment, menentukan indicator kinerja, menen-tukan } \\
\text { entitas yang bertanggung jawab dalam divisi TI, } \\
\text { membuat dokumentasi terkait proses yang belum di- } \\
\text { miliki atau diterapkan. }\end{array}$ \\
\hline PO8 & $\begin{array}{l}\text { Kualitas yang buruk tidak dapat diiden- } \\
\text { tifikasi sehingga akan merugikan penggu- } \\
\text { na layanan TI. Kualitas yang buruk me- } \\
\text { mungkinkan terjadinya software rusak dan } \\
\text { modifikasi perangkat lunak yang disengaja } \\
\text { sehingga dapat terjadinya tindak penipuan. }\end{array}$ & $\mathrm{H}$ & $\begin{array}{l}\text { Membuat Prosedur dan Pedoman terkait Manage Qua- } \\
\text { lity, menentukan indikator kinerja, menentukan entitas } \\
\text { yang bertanggung jawab dalam divisi TI, membuat do- } \\
\text { kumentasi terkait proses yang belum dimiliki atau di- } \\
\text { terapkan dan menggunakan tools untuk membantu ak- } \\
\text { tifitas proses. }\end{array}$ \\
\hline AI2 & $\begin{array}{l}\text { Pengembangan lebih lanjut terhambat dan } \\
\text { mengakibatkan gangguan operasional ka- } \\
\text { rena aplikasi tidak sesuai dengan kebutu- } \\
\text { han yang baru. Serta keamanan TI yang } \\
\text { kurang mengakibatkan terjadinya korupsi } \\
\text { data dan modifikasi data yang tidak di- } \\
\text { perbolehkan dilakukan dengan sengaja. }\end{array}$ & $\mathrm{H}$ & $\begin{array}{l}\text { Membuat Prosedur dan Pedoman terkait Acquire and } \\
\text { maintain application software, menentukan entitas ya- } \\
\text { ng bertanggung jawab dalam divisi TI dan membuat } \\
\text { dokumentasi terkait proses yang belum dimiliki atau } \\
\text { diterapkan. }\end{array}$ \\
\hline AI4 & $\begin{array}{l}\text { Tidak mengetahui seberapa siap pengguna } \\
\text { dalam memanfaatkan aplikasi baru, sehi- } \\
\text { ngga mengakibatkan pengguna tidak siap } \\
\text { meggunakan perangkat lunak baru. }\end{array}$ & M & $\begin{array}{l}\text { Membuat Prosedur dan Pedoman terkait Enable Ope- } \\
\text { ration and Use, menentukan indikator kinerja, menen- } \\
\text { tukan entitas yang bertanggung jawab dalam divisi TI } \\
\text { dan menggunakan tools untuk membantu aktifitas pro- } \\
\text { ses. }\end{array}$ \\
\hline AI7 & $\begin{array}{l}\text { Terjadinya eror pada aplikasi karena tidak } \\
\text { dilakukan pengujian, sehingga mengham- } \\
\text { bat pekerjaan pengguna layanan TI peru- } \\
\text { sahaan dan kualitas layanan TI semakin } \\
\text { memburuk. }\end{array}$ & M & $\begin{array}{l}\text { Membuat Prosedur dan Pedoman terkait Install and } \\
\text { accredit solutions and changes, menentukan indikator } \\
\text { kinerja, menentukan entitas yang bertanggung jawab } \\
\text { dalam divisi TI, membuat dokumentasi terkait proses } \\
\text { yang belum dimiliki atau diterapkan dan menggunakan } \\
\text { tools untuk membantu aktifitas proses. }\end{array}$ \\
\hline
\end{tabular}

software dan dokumentasi laporan terkait proses untuk meningkatkan kinerja divisi dalam mengelola proyek TI PT XYZ.

\section{AI4 Enable operation and use}

Kondisi Kepatuhan dan Kebutuhan TI yang seharusnya dimiliki proses ini adalah dengan memiliki dokumen SOP Eneble Operation and Use dan dokumentasi laporan terkait proses.

AI7 Install and accredit solutions and changes Kondisi Kepatuhan dan Kebutuhan TI yang seharusnya dimiliki proses ini adalah dengan memiliki dokumen SOP Acquire and Maintain Technology Infrastructure dan dokumentasi laporan terkait proses.

Rekomendasi perancangan dokumen yang diberikan untuk PT XYZ sesuai aspek people, process dan technology dijelaskan pada Tabel 7.

\section{Analisis Gap}

Analisis gap dilakukan untuk mengetahui seberapa besar kesenjangan yang terdapat pada setiap proses prioritas, sehingga dapat mengetahui dampak yang mungkin muncul dan memberikan risiko bagi bisnis. Berikut hasil analisis gap akan dijelaskan pada Tabel 8.

\section{Analisis Risiko}

Analisis Risiko dilakukan berdasarkan pada laporan analisis risiko yang telah dilakukan Divisi TI PT XYZ. Adapun parameter untuk kemungkinan (probability) dan dampak terhadap suatu risiko yang dapat terjadi. Parameter kemungkinan (probability) dan dampak pada analisis risiko berikut ini merupakan parameter yang menunjukan frekuensi terjadinya risiko serta dampak yang terjadi akibat risiko. Parameter probability berdasarkan parameter yang digunakan Divisi TI PT XYZ dalam mengidentifikasi risiko akan dijelaskan pada Tabel 9.

Hasil analisis risiko yang didapat mencakup penjelasan dampak risiko, probability, dan rekomendasi yang diberikan sebagai respon dari risiko yang teridentifikasi. Analisis risiko berikut telah dipetakan berdasarkan parameter tingkat risiko dan dijelaskan pada Tabel 10.

\section{Kesimpulan}

1. Nilai maturity level Tata Kelola TI PT XYZ saat ini berdasarkan framework COBIT 4.1 proses PO adalah 1,5, proses AI adalah 1,47 dan rata-rata kedua proses adalah 1,49 dengan target yang harus dicapai adalah pada level tiga (3).

2. Berdasarkan assessment maturity level, ratarata kondisi tata kelola TI PT XYZ pada saat 
ini adalah pada tahap Initial menuju Repeatable. Kondisi yang terjadi pada level 1,49 yaitu Divisi TI PT XYZ telah menyadari kepentingan suatu proses dan pada beberapa proses telah berjalan aktivitas yang berulang namun masih ditemukan aktivitas yang merupakan inisiatif individu.

3. Rekomendasi perancangan tata kelola TI Divisi TI disusun berdasarkan pemetaan proses prioritas antara lain rekomendasi kebijakan, prosedur baku, template dokumen, formulir data, struktur organisai rekomendasi dan usulan teknologi.

\section{Referensi}

[1] Tan, W., Cater-Steel, A., \& Toleman, M., Implementing IT Service Management: A Case Study Focussing On Critical Success Factors, 2009.

[2] Agus, P. U., \& Novita, M, Analisis Tata Kelola Teknologi Informasi (IT Governance) Pada Bidang Akademik dengan Cobit Framework Studi Kasus pada Universitas Stikubank Semarang, 2011.

[3] Peraturan Menteri BUMN, Keputusan PER01/MBU/2011, 2011.

[4] Peraturan Menteri BUMN, PER 02/MBU/ 2013, 2013.
[5] IT Governance Institute, COBIT 4.1 Framework, Control Objectives, Management Guidelines, Maturity Models, IT Governance Institute, 2007.

[6] Ricoida, D., I. \& Mulyati, Studi Penerapan IT Governance Menggunakan Framework COBIT dalam Mendukung Layanan TI (Studi Kasus AMIK XYZ), 2012.

[7] Craig, S., Cecere, M., Young, G. O. \& Lambert, N, IT Governance Framework: Structures, Processes, and Communication, 2005.

[8] Jogiyanto, H.M dan Abdillah, W, Sistem Informasi Teknologi Informasi, Yogyakarta, 2011.

[9] Supriatna, A, Implementasi Framework COBIT 4.1 dalam Tata Kelola Teknologi Informasi dan Komunikasi di Diskominfo Kabupaten Subang, 2011.

[10] Tjhin, U. V, Audit Domain Acquire And Implement Dengan COBIT 4.1 Pada PT Erajaya Swasembada Tbk ComTech Vol. 5 No. 2, 1088

[11] S, Wakhinuddin, Analisis Gap. [Available]: https://wakhinuddin.wordpress.com/2009/11 /24/analisis-gap/, [Diperoleh 6 April 2016].

[12] Awalianti, A., \& Isgiyarta, J, Penerapan dan Fungsi Manajemen Risiko Fluktuasi Harga Batu Bara Berdasarkan ISO 31000., 2014 